\title{
DOENÇAS E SINDROMES ASSOCIADAS À MIASTENIA GRAVE EM UM GRUPO DE 304 PACIENTES
}

\author{
J. LAMARTINE DE ASSIS * \\ PAULO E. MARCHIORI *** \\ ANTONIO A. ZAMBON *** \\ MILBERTO SCAF'H **
}

A partir de meados da década de 50 o interesse dos pesquisadores se voltou para aspectos epidemiológicos e imunológicos da miastenia grave (MG). Nessa primeira fase da evolução dos conhecimentos sobre a patogênese da doença, os estudos com base epidemiológica e imunológica iniciados quase concomitantemente por Simpson ${ }^{26}$ e outros autores ${ }^{12,16,29}$ lcvantaram a hipótese auto-imune. Desde então apareceram numerosos registros de doenças e sindromes associadas com MG, em particular as de natureza auto-imune 1, 4, 6, 17, 18, 28,31 .

\section{MATERIAL E METODOS}

Fol feito levantamento de doenças associadas com MG em um grupo de 304 pacientes miastênicos, a grande maioria dos quais examinados e acompanhados na clínica Neurológica do Hospital das Clínicas da FMUSP. Os casos de associaçóes com doenças auto-imunes e outras pertencentes ao grupo em estudo são apresentados na tabela 1. Foi feito estudo comparativo entre os casos presentes e os de outros autores.

\section{RESULTADOS}

A associação de MG com timoma ocorreu em 17 pacientes (5,5\%): em três a MG apareceu após a cirurgia (dós meses em dois pacientes e três anos em outro); um paciente desenvolveu pênfigo foliáceo; em 13 pacientes a MG foi a manifestação inicial.

$A$ associação com disfunção tireoidiana ocorreu em 10 pacientes $(3,3 \%)$ : em 9 havia hipertireoidismo $(3,0 \%)$ e em um $(0,3 \%)$ hipotireoidtsmo. $O$ hipertireoidismo antecedeu a MG em $44 \%$ dos casos, foi simultaneo em $33 \%$ e sucedeu o início da sintomatologia miastênica em $22 \%$. Em um paciente não ficou esclarecida a época em que se iniciou a đisfunção tireoidiana.

A associação com doença reumatb́ide (DR) ocorreu em seis pacientes (2\%): em um paciente do sexo feminino as manifestações articulares apareceram cerca de 20

Trabalho realizado no Serviço de Clínica Neurológica da Dívisão de Neurologia do Departamento de Neuropsiquiatria (Prof. Dr. Horácio Martins Canelas) da Faculdade de Medicina da Universidade de São Paulo (FMUSP): * Professor Adjunto; ** Professor Livre Docente; ** Médico Assistente do Hospital das Clínicas, FMUSP. 


\begin{tabular}{lcc}
\hline Doenças e sindromes & $\begin{array}{c}\text { Pacientes } \\
\text { (número) }\end{array}$ & $\%$ \\
\hline \hline Timoma & 17 & 5,7 \\
Tireopatia & 15 & 5,0 \\
$\quad$ hipertireoidismo & 9 & 3,0 \\
Artrite reumatóide & 1 & 0,3 \\
Polimiosite & 6 & 2,0 \\
Escleroderma * & 2 & 0,6 \\
Sindrome de Sjogren & 2 & 0,6 \\
Esclerose multipla & 2 & 0,6 \\
Milocardite e retite crônica & 1 & 0,3 \\
Síndrome de Raynaud & 1 & 0,3 \\
Penfigo folíaceo ** & 1 & 0,3 \\
Vitiligo *** & 1 & 0,3 \\
Pneumonite intersticial & 1 & 0,3 \\
Miocardite e retite crônica **** & 1 & 0,3 \\
Total & 1 & 0,3 \\
\hline
\end{tabular}

Tabela 1-Doengas e sindromes associadas a miastenia grave em série de 304 palcientes. Legenda: * dois casos de esclerose sistemica progressiva, sendo um associadio a polimiosite: lambos desenvolveram sindrome miastenica após uso de D-penicilina; * um caso de penfigo folidceo associado timoma; *** vitiligo associado a hipertireoidismo e paralisia periodica; **** achado die necropsia.

anos após remissão completa da MG e se mantém até o momento; em outro, também do sexo feminino, ocorreu evolução similar, porém, após periodo mais curto de remissão da MG.

Dois pacientes com escleroderma desenvolveram sindrome miastenica (SMG) após uso prolongado de D-penicilamina. Uma mulher de 52 anos de idade com sindrome de Sjögren iniciada há seis anos apresentou, recentemente, sintomas de MG. Outra mulher com 39 anos de idade com síndrome seca há dois anos, começou a manifestar sintomas miastenicos um ano depois; em ambas foi confirmada MG. Uma mulher de 38 anos de idade desenvolveu, simultaneamente, esclerose múltipla e MG. Um homem com 28 anos de idade exibiu associação de MG com polimiosite e a imunossupressão com prednisona fol seguida de melhora importante de ambas as doenças. $O$ exame necroscóplo de uma criança de três anos de idade com MG, iniciada aos dois anos, mostrou miocardite inespecifica e retite crónica. Uma paciente com 35 anos de idade apresentou, após um ano do início da MG, fenômeno de Raynaud que persiste até o momento. Foram registrados três casos de associaçóes múltiplas: um homem de 24 anos de idade com vitiligo progressivo, que se iniciou há seis anos, apresentou hipertireoidismo e, simultaneamente, crises repetidas de paralisia perí́dica; quatro meses depois o paciente desenvolveu MG; uma mulher com 76 anos de idade, com MG e timoma, foi submetida a imunossupressão com prednisona a radioterapia da regío tímica (3000x) com melhora importante dos sintomas; tres anos após o inicio da MG e dols anos depols do tratamento, apareceu penfigo folláceo; um homem 
com 52 anos de idade, com escleroderma e polimiosite, apresentou síndrome miastenica após uso prolongado de D-penicilamina.

\section{COMENTARIOS}

Os pacientes com MG são considerados como tendo maior incidência de associações com certas doenças ou síndromes, em particular as mediadas imunologicamente 1, 4, 6, 11, 18-28. Para Simpson 27, 28, as tireopatias, artrite reumatóide e anemia perniciosa foram observadas mais frequentemente em seus pacientes miastênicos do que seria aceito como mera coincidência, fato confirmado por outros 18-21, 23. A dificuldade maior é à avaliação da incidência da MG e outras afecções consideradas como auto-imunes na população. Apesar dessa dificuldade e das pesquisas serem realizadas em centros para onde convergem maior número de pacientes com MG, o que poderia falsear as estimativas, existe um consenso quanto a incidência de certas doenças como tireopatias, em particular o hipertireoidismo. Persistem, contudo, algumas controvérsias a respeito de associações com outras doenças auto-imunes, como o lupus eritematoso ${ }^{11}$. Não obstante a falta de estudos estatísticos adequados parece que muitas dessas associações, por vezes múltiplas em um mesmo paciente $3,4,6,11,22,24,25$ apoiam a patogenia imunológica da MG. Este fato é reforçado pela presença, em cerca de $40 \%$ dos soros miastênicos, de extensa gama de auto-anticorpos 1, 5-7, 9, 13, 20, 24, 27 além do anticorpo antirreceptor de acetilcolina encontrado em cerca de $90 \%$ de soros miastênicos humanos 2, 8, 10, 11, 17 .

No grupo presente, os timomas e tireopatias foram as doenças mais frequentemente associadas à MG (5-6\%). Nos pacientes timomatosos a MG foi a manifestação inicial ocorrendo em $76,4 \%$ dos casos. No grupo das tireopatias ocorreu predomínio franco do hipertireoidismo $(3,0 \%)$ sobre o hipotireoidismo $(0,3 \%)$, o que também está de acordo com outros autores $21-23,27,28,31$. Na maioria dos casos (44\%) a MG sucedeu o hipertireoidismo por períodos variáveis de tempo, o que está em desacordo com a literatura, e poucas vezes coincidịu haver melhora da sintomatologia miastênica com a normalização da função tireoidiana. $O$ início simultâneo das duas doenças ocorreu em $33 \%$ dos casos o que se aproxima do observado por outros 14, 23. Apenas em um caso o hipertireoidismo era parte de associações múltiplas ( $M G$, vitiligo e paralisia periódica): Trata-se de associação muito rara, não existindo na literatura compulsada casạ semelhante; apenas uma publicação, até o momento, faz referência à associação. vitiligo, MG e hipertireoidismo 4. A associação com doença reumatóide aparece em seguida, mas em porcentagem bem inferior (2\%) às duas primeiras. Neste particular a série presente se comporta de modo semelhante a outras séries publicadas 18, 19, 21, 27, 31. A participação das demais doenças e síndromes foi pouco significativa, estando abaixo de $1 \%$. O escleroderma e a polimiosite compareceram com $0,6 \%$ cada, sendo de notar que na primeira a D-penicilamina induziu o desenvolvimento de síndrome miastênica, tanto num caso isolado de escleroderma como em outro associado com polimiosite. Fato digno de registro na série presente foi o achado pós-morte, em uma criança miastênica, de miocardite e retite crônica. 


\section{RESUMO}

Foram realizados estudos epidemiológico e clínico de doenças e síndromes associadas em um grupo de 304 pacientes miastênicos. Foram apresentadas projeções comparativas entre os casos presentes e os de outros autores.

\section{SUMMARY}

Myasthenia gravis and both syndromes and diseases associated in a group of 304 patients.

Epidemiologic and clinic studies of both diseases and syndromes associated in a group of 304 myasthenic patients were made. A comparative projection between the present cases and those of other authors was presented.

\section{REFERPNCIAS}

1. ADNER, M. M.; SHERMAN, J. D.; ISE, C.; SCHWAB, R. S. \& DAMESHEK, W. A. - An immunologic survey of 48 patients with myasthenia gravis. New Engl. J. Med. 271:1327, 1964.

2. AHARONOV, A.; ABRAMSKY, O.; TARRAB-HAZDAI, R. \& FUCHS, $\mathbf{s}$. Humoral antibodies to acetylcholine receptor in patients with myasthenia gravis. Lancet 1:340, 1975.

3. BOSCH, E. P.; REITH, P. E. \& GRANNER, D. K. - Myasthenia gravis and Schmidt syndrome. Neurology (Minneapolis) 27:1179, 1977.

4. BOUdIN, C.; LHUILLIER, M.; SHAISON, G..; PATRI, B. \& GIRAULT, F. Myasthenia, vitiligo, maladie de Basedow. Ann. Méd. int. 123:861, 1972.

5. GELD, H. VAN DER; FELTKAMP, T. E. W.; LOGHEM, J. J. VAN DER; OOSTERHUIS, H. J.G.H. \& BIEMOND, A. - Multiple antibody production in myasthenia gravis. Lancet 2:373, 1963.

6. HAUSMANOWA-PETRUSEWICZ, I.; CHORZELSKI, T. \& STRUGALSKA, H. Three year observation of a myasthenic syndrome with other autoimmune syndromes in a patient with thymoma. J. neurol. Sci. 9:273, 1969.

7. KORNGUTH, S. E.; HANSON, J. C. \& CHUN, R. W. M. - Antineuronal antibodies in patients having myasthenia gravis. Neurology (Minneapolis) 20:749, 1970.

8. LEFVERT, A. K.; BERSTRöM, K.; M.TELL, G.; OSTERMAN, P. O. \& PISHANER, R. - Determination of acetylcholine receptor antibody in myasthenia gravis: clinical usefulness and pathogenic implications. J. Neurol. Neurosurg. Psychiat. 41:394, 1978.

9. LEONE, G.; TONALI, P.; TAVIANE, A. \& LOVASTE, A. G. - Platelet autoantibodies in myasthenia gravis. New Engl. J. Med. 297:1402, 1977.

10. LINDSTROM, J. M.; SEYBOLD, M. E.; LENNON, V. A.; WHITTINGHAM, S. \& DUANE, D. D. - Antibody to acetylcholine receptor in myasthenia gravis: prevalence, clinical correlates, and diagnostic value. Neurology (Minneapolis) 26:1054, 1976.

11. LISAK, R. P. \& BARCHI, R. L. - Myasthenia Gravis. Saunders, Philadelphia, 1982.

12. MARSHALL, A. H. E. -- Experimental thymic lesions resembling those of myasthenia gravis. Lancet 1:1030, 1961.

13. MCFARLIN, D. E. - Myasthenia gravis. In M. Samter (ed.) - Immunological Diseases. Little-Brown, Boston, 1978, pg. 1383.

14. MILLIKAN, C. K. \& HAINES, S. F. - The thyroid gland in relation to neuromuscular disease. Arch. int. Med. 92:5, 1953. 
15. NAMBA, T.; NAKATA, $Y$. \& GROB, D. - The role of humoral and cellular immune factors in neuromuscular block in myasthenia gravis. Ann. N. Y. Acad. Sci. $274: 493$, 1976.

10. NASTUK, W. L.; STRAUSS, A. J. L. \& OSSERMAN, K. E. - Search for a neuromuscular blocking agent in the blood of patients with myasthenia gravis. Amer. J. Med. $26: 394,1959$.

17. ODA, K.; GOTO, I.; KUROIWA, Y.; ONOUE, K. \& ITO, Y. - Myasthenia gravis: antibodies to acetylcholine receptor with human and rat antigens. Neurology (NY) 30:543, 1980.

18. OOSTERHUIS, H. J. G. H. - Studies in myasthenia gravis: a clinical study of 180 patients. J. neurol. Sci. 1:512, 1964.

19. OOSTERHUIS, H. J. G. H. \& HAAS, W. H. D. - Rheumatic diseases in patients with myasthenia gravis. An epidemiological and clinical investigation. Acta neurol. scand. 44:219, 1968.

20. OSSERMAN, K. E.; TSAIRIS, P. \& WEINER, L. B. - Myasthenia gravis and thyroid disease: clinical and immunologic correlation. J. Mt. Sinai Hosp. 34:469, 1967.

21. OSSERMAN, K. E. - Myasthenia Gravis. Grune and Stratton, New York, 1958.

22. REZNIK, M. - Deux cas de syndrome myasthénique avec thymome, polymyosite, myocardite et thyroidite. J. neurol. Sci. $22: 341,1974$.

23. ROWLAND, L. P. - Myasthenia gravis. In E. S. Goldensohn \& S. H. Appel Scientific Approaches to Clinical Neurology. Lea \& Febiger, 1977, pg. 1018.

24. SAGAR, H. J.; GELSTHORPE, K.; WARD-MIFORD, A. \& DAVIES-JONES, G. A. B. - Clinical and immunological associations in myasthenia gravis. I: autoantibodies. J. Neurol. Neurosurg. Psychiat. 43:967, 1980.

25. SAMMAN, P. D. - Ulcerative colitis, myasthenia gravis, atopical lichen planus, alopecia areata, vitiligo. Proc. roy. Soc. Med. 67:195, 1974.

26. SIMPSON, J. A. - Myasthenia gravis: a new hypothesis. Scott. med. J. 5:419, 1960.

27. SIMPSON, J. A. - Myasthenia gravis as an autoimmune disease: clinical aspects. Ann. N. Y. Acad. Sci. 135:506, 1966.

28. SIMPSON, J. F.; WESTERBERG, M. R. \& MAGER, K. R. - Myasthenia gravis. An analysis of 295 cases. Acta neurol. scand. 42 (suppl. 23), 1966.

29. STRAUSS, A. J. L. ; SEFGAL, B. C.; HSU, K. C.; BURHOLDER, P. M.; NASTUK, W. L. \& OSSERMAN, K. E. - Immunofluorescence demonstration of a muscle binding complement-fixing serum globulin fraction in myasthenia gravis. Proc. Soc. exp. Biol. 105:184, 1960.

30. WHITTINGHAM, S. \& MACKAY, I. R. - The pemphigus antibody and immunopathies affecting the thymus. Brit. J. Derm. 84:1, 1971.

31. WOLF, M. S.; ROWLAND, P. L.; SCHOTLAND, L. D.; MCKINNEY, S. A.; HOEFER, A. F. P. \& ARANOW Jr., H. - Myasthenia as an autoimmune disease: clinical aspects. Ann. N. Y. Acad. Sci. 135:517, 1966.

Clínica Neurologica, F'MUSP - Caixa Postal 3461 - 01000, São Paulo, SP - Brasil. 